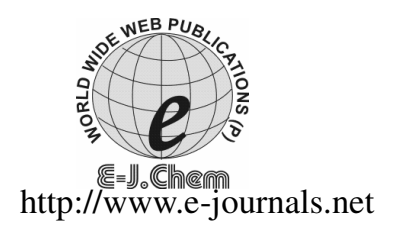

ISSN: 0973-4945; CODEN ECJHAO

E-Journal of Chemistry

2011, 8(4), 1644-1653

\title{
Decolorization Kinetics and Thermodynamics of Auramine Lake Yellow $O$ on Expanded Graphite Loaded with Titania
}

\author{
XIU-YAN PANG \\ College of Chemistry and Environmental Science, Hebei University \\ Baoding 071002 People' Republic of China \\ pxy833@163.com
}

Received 2 January 2011; Accepted 28 February 2011

\begin{abstract}
In order to investigate the decolorization characteristics of expanded graphite (EG) loaded with titania for auramine lake yellow $\mathrm{O}$ adsorbate, the adsorbent is prepared with 50 mesh natural graphite as raw materials, potassium permanganate as oxidant and vitriol, tetranbutyl titanate as intercalation compound. The expanded volume of EG loaded with titania is $320 \mathrm{~mL} / \mathrm{g}$. We detect the equilibration time, influence of ionic strength and initial concentration of the adsorbate on decolorization rate. Based on pseudo first-order and second-order kinetic model, the decolorization model is discussed. Decolorization rate and activation energy were calculated. Studies show that decolorization rate of EG loaded with titania for auramine lake yellow $\mathrm{O}$ decrease with the increase of the adsorbate initial concentration and increase with the increase of ionic strength; the decolorization process can be well described by the pseudo second-order kinetic model; decolorization equilibrium time and half decolorization time decrease with the increase of temperature.
\end{abstract}

Keywords: Expanded graphite, Adsorption, Photodegradation, Auramine lake yellow O, Kinetics, Thermodynamics

\section{Introduction}

Expanded graphite (EG) is from graphite intercalation compounds. Under oxidation, the graphite layer can be opened, a number of organic and inorganic compounds, elements can be inserted, and remain in the graphite layers to form a graphite intercalation compounds (also known as expandable graphite). EG is prepared with expandable graphite expanded at high temperature such as $900 \sim 1000{ }^{\circ} \mathrm{C}^{1,2}$. EG has a worm-like shape and network-like porous structure with aperture ranging from several nanometer to hundreds micron. It also holds low density, high chemical stability under high or low temperature ${ }^{3,4}$. Experiment 
has proved that the greater expanded volume of EG possess, the larger amount of industrial oil and dye molecules can be adsorbed, so it has been used as adsorbent of industrial oils and dyes ${ }^{5,6}$.

In the adsorption treatment of dyes with EG, Wang et al. ${ }^{7}$ pressed the worm-like particles into low-density plate of $0.1 \mathrm{~g} / \mathrm{cm}^{3}$, then the plate was used to treat dye wastewater from woolen mill. Yang ${ }^{8}$ et al. investigated the influencing factors in adsorption of dyes and indicated that the adsorption capacity of EG is influenced by various factors, not only the expanded volume, primary concentration of dyes, contact time, but also the amount of expanded graphite, $\mathrm{pH}$ and temperature. The adsorption of basic fuchsine, auramine lake yellow $\mathrm{O}$ and acid brilliant red on EG is a spontaneous process ${ }^{9}$, both dyes' molecular weight and molecular structure affect adsorption type and saturation adsorbance. Linear relationship was obtained between adsorption capacity and EG specific surface area. Higher ionic strength and proper $\mathrm{pH}$ values would improve adsorption capacity. Adsorption kinetics of EG for acid brilliant red $3 \mathrm{~B}^{10}$ showed adsorption process has small activation energy and it can be well described by the pseudo second-order kinetic model. Internal diffusion appears to be the rate-limiting step for the adsorption process.

In chemical oxidation of dyes, nano- $\mathrm{TiO}_{2}$ is the most commonly used photocatalyst. Under ultraviolet radiation, $\mathrm{TiO}_{2}$ has a strong ability to generate $\mathrm{OH}$, which will ultimately enable complete oxidation of organic pollutants in water and generates $\mathrm{CO}_{2}, \mathrm{H}_{2} \mathrm{O}$ and other simple inorganic ions (such as $\mathrm{NO}_{3}{ }^{-}, \mathrm{SO}_{4}{ }^{2-}, \mathrm{PO}_{4}{ }^{3-}$ and halogen, etc.). So far, more than 3000 kinds of refractory organic compounds have been found being degraded by $\mathrm{TiO}_{2}$ under ultraviolet radiation ${ }^{11}$. To recycle this catalyst after reaction, $\mathrm{TiO}_{2}$ is often loaded by some kinds of carriers ${ }^{12}$. The used carriers often have little adsorption capacity for pollutant, which would decrease the degradation capability of $\mathrm{TiO}_{2}$.

EG loaded with titania is a kind of adsorbent with porous structure and loading titania ${ }^{13,14}$, it couples adsorption of EG and photo-catalysis of $\mathrm{TiO}_{2}$ together. In this experiment, EG loaded with titania was prepared and its degradation thermodynamics and kinetics for auramine lake yellow $\mathrm{O}$ is discussed. Results are compared with the single adsorption of EG and photo-catalysis of titania. Possible decolorization mechanism is discussed.

\section{Experimental}

EG loaded with titania was prepared with potassium permanganate as oxidant, sulfuric acid and tetrabutyl titanate as intercalation reagent ${ }^{14}$. Reaction condition is: C: $\mathrm{KMnO}_{4}: \mathrm{H}_{2} \mathrm{SO}_{4}$ (diluted to 75\%): tetrabutyl titanate $=1: 0.5: 3.0: 0.4$. The reaction lasts $60 \mathrm{~min}$ in $45{ }^{\circ} \mathrm{C}$ water bath, then product was transferred into beaker and washed with water until $\mathrm{pH}=$ $6.0 \sim 7.0$ and washing water without color of potassium permanganate. After dipping in water for 2-3 h, the product was filtrated and then dried at $60 \sim 80^{\circ} \mathrm{C}$, expandable graphite was obtained. Expandable graphite was expanded at $900{ }^{\circ} \mathrm{C}$ for $10 \mathrm{~s}$, then EG loaded with titania was obtained. To illustrate the existence of intercalation compound and its form, graphite, expandable graphite and EG were characterized with XRD (Y-2000 X-Ray powder diffraction instrument). As showed in Figure 1, anatase $\mathrm{TiO}_{2}$ was found in expandable graphite and titania was found in EG. Structural parameters of the prepared adsorbent were characterized by expanded volume, surface area and total pore cubage. These data were detected with BET $\mathrm{N}_{2}$ adsorption by micromeritics instrument corporation TriStar II 3020 V1.02 (as listed in Table 1.) 

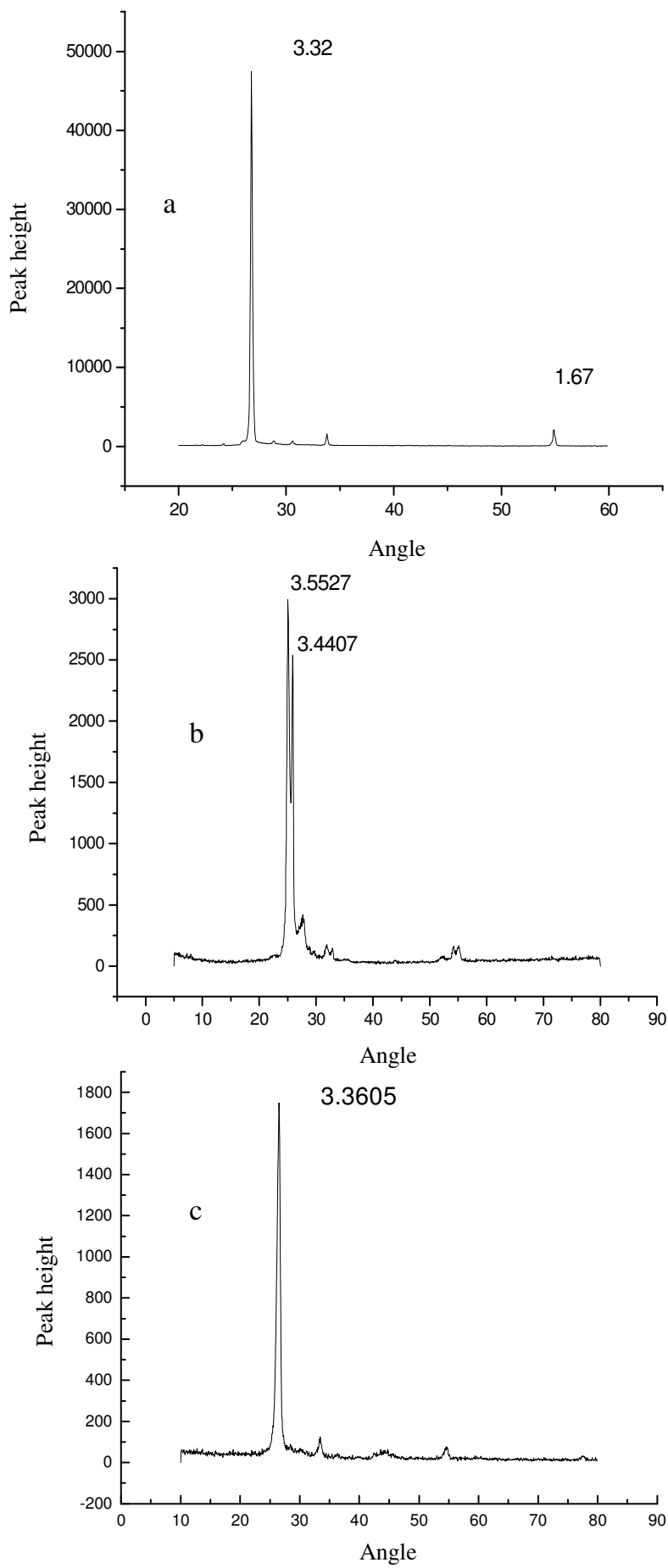

Figure 1. XRD of graphite expandable graphite and EG (a) graphite; (b) expandable graphite; (c) EG loaded with titania 
Table 1. Structural parameter of EG loaded with titania*

\begin{tabular}{ccc}
\hline $\begin{array}{c}\text { Expanded volume, } \\
\mathrm{mL} / \mathrm{g}\end{array}$ & $\begin{array}{c}\text { Specific surface area, } \\
\mathrm{m}^{2} / \mathrm{g}\end{array}$ & $\begin{array}{c}\text { Pore volume, } \\
\mathrm{cm}^{3} / \mathrm{g}\end{array}$ \\
\hline 320 & 20.3285 & 0.073891 \\
\hline
\end{tabular}

"Detection condition: Analysis adsorptive: $\mathrm{N}_{2}$; Sample mass: $0.1688 \mathrm{~g}$; Equilibration interval: $10 \mathrm{~s}$; Surface area or pore volume of pores between $1.7000 \mathrm{~nm}$ and $300.0000 \mathrm{~nm}$ diameter

\section{Adsorbate characteristics}

Auramine lake yellow $\mathrm{O}$ with biphenyl methane structure was selected as reference compounds. Molecular structures and molecular weight of the dye was shown in Table 2. It was supplied by Yuhua trade company, Tientsin, China. Simulated dye wastewater was prepared by dissolving the auramine lake yellow $\mathrm{O}$ in distilled deionized water at various concentrations. Absorbance value was recorded at the wavelength for maximum absorbance $\left(\lambda_{\max }\right)$ corresponding to dye as shown in Table 2.

Table 2. Chemical structure and molecular weight of dyes used in experiment

\begin{tabular}{cccc}
\hline Dye & Structure & $\begin{array}{c}\text { Molecular } \\
\text { weight }\end{array}$ & $\lambda_{\max }, \mathrm{nm}$ \\
\hline $\begin{array}{c}\text { Auramine lake } \\
\text { yellow } \mathrm{O}\end{array}$ & $\left.\left(\mathrm{CH}_{3}\right)_{2} \mathrm{~N}-\longrightarrow C-\mathrm{N}_{\mathrm{N}}-\mathrm{CH}_{3}\right)_{2}$ & 318.5 & 430 \\
\hline
\end{tabular}

\section{Determination of decolorization rate}

Batch decolorization experiments were carried in $250 \mathrm{~mL}$ beaker with the mass of adsorbent to volume of dye solution was standardized at $m / v=0.05 \mathrm{~g} / 0.1 L=0.5 \mathrm{~g} / L$. Decolorization under different condition were compared. Method I: decolorization was carried in dark with EG loaded with titania as adsorbent. Method II: decolorization was carried under UV irradiation with EG loaded with titania as adsorbent. Method III: decolorization was carried under UV irradiation with no adsorbent. Absorbency of solution was detected at different time. Total decolorization rate, adsorption decolorization rate, UV photodegradation decolorization rate and UV revulsive titania photodegradation decolorization rate were calculated according to equation (1).

$$
D=\left(A_{0}-A_{t}\right) / A_{0}{ }^{*} 100 \%
$$

$D$, Decolorization rate, $\% ; A_{o}$, absorbency before decolorization; $A_{t}$, absorbency at moment $\mathrm{t}$.

\section{Decolorization rate of dye in the influence of ionic strength}

$\mathrm{NaCl}$ and $\mathrm{Na}_{2} \mathrm{SO}_{4}$ were used to investigate their influence on decolorization rate and their concentration changed from 0 to $50 \mathrm{~g} / \mathrm{L}$. Concentration of auramine lake yellow $\mathrm{O}$ was set as $50 \mathrm{mg} / \mathrm{L}$.

\section{Decolorization kinetics experiment}

In decolorization kinetics experiment, a series of desired dye concentration and fixed volume of $100 \mathrm{~mL}$ were placed in vessels where they were brought into contact with EG loaded with titania at $5{ }^{\circ} \mathrm{C}, 25^{\circ} \mathrm{C}$ and $45^{\circ} \mathrm{C}$, respectively. The mass of adsorbent to volume of solution was standardized at $m / v=0.0500 \mathrm{~g} / 0.1 \mathrm{~L}=0.5000 \mathrm{~g} / \mathrm{L}$. Decolorization was carried under UV irradiation. Absorbency of dye solution corresponding to different decolorization time was analysed until the absorbency kept as a constant and it was used to calculate the decolorization rate at different moment according to equation (1). 


\section{Results and discussion}

\section{Influence of adsorbate concentration and decolorization time on decolorization rate}

Figure 2 shows decolorization rate is the function of decolorization time and auramine lake yellow $\mathrm{O}$ concentration. Equilibrium time was about $5.0 \mathrm{~h}$ in dark at $25{ }^{\circ} \mathrm{C}$ (single adsorption of EG); it does not affected by dye concentration. However, decolorization rate combined EG adsorption and titania photo-degradation increases in a decreasing speed with the increase of decolorization time. At the same time, decolorization rate decrease with the increase of auramine lake yellow $\mathrm{O}$ concentration. The results illustrate decolorization is caused totally by EG adsorption and titania photodegradation.

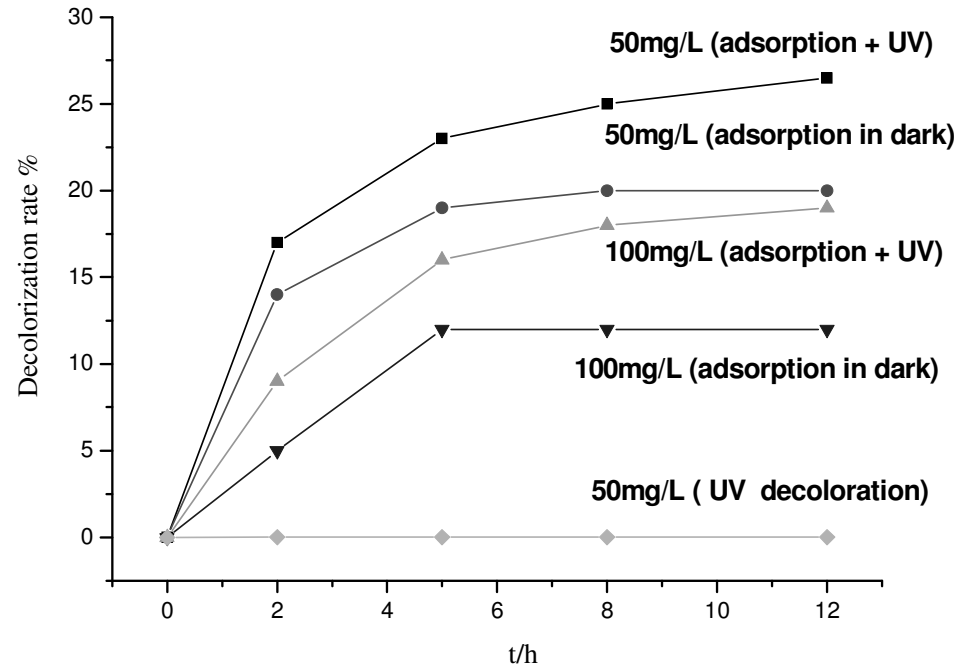

Figure 2. Decolorization equilibrium time of auramine lake yellow $\mathrm{O}$

\section{Influence of ionic strength on decolorization}

To investigate the influence of ionic strength on decolorization rate of auramine lake yellow $\mathrm{O}, \mathrm{NaCl}$ and $\mathrm{Na}_{2} \mathrm{SO}_{4}$ were used to adjust ionic strength at a ranging of $0 \sim 50 \mathrm{~g} / \mathrm{L}$. The results are showed in Figure 3. It indicates that the presence of $\mathrm{NaCl}$ and $\mathrm{Na}_{2} \mathrm{SO}_{4}$ enhances decolorization of dyes. Absolute ionization of $\mathrm{NaCl}, \mathrm{Na}_{2} \mathrm{SO}_{4}$ in solution makes them form negative and positive ions, there don't exist competitive adsorption of these ion with dye molecule. On the other hand, electrostatic interaction between dye and adsorbent decreases with the increase in ionic strength probably because of the suppression of the electric double layer ${ }^{15}$ and hydrophobic attraction increases due to the "salting-out" effect. Over a range of $10.0 \mathrm{~g} / \mathrm{L}$ to $50.0 \mathrm{~g} / \mathrm{L}$, the influence of $\mathrm{NaCl}$ is more obvious than that of $\mathrm{Na}_{2} \mathrm{SO}_{4}$ on decolorization rate.

\section{Influence of temperature and adsorbate concentration on equilibrium time}

In Figure 4, decolorization rate is shown as a function of time and adsorbate concentration, decolorization occurs more rapidly at higher temperature. It takes only $2.0 \mathrm{~h}$ to reach the decolorization equilibrium at $35{ }^{\circ} \mathrm{C}$, while it takes about $5.0 \mathrm{~h}$ at $5{ }^{\circ} \mathrm{C}$. Initial dye concentration does not have a significant effect on the equilibrium time. However, decolorization rate decrease with the increase of auramine lake yellow $\mathrm{O}$ concentration. 


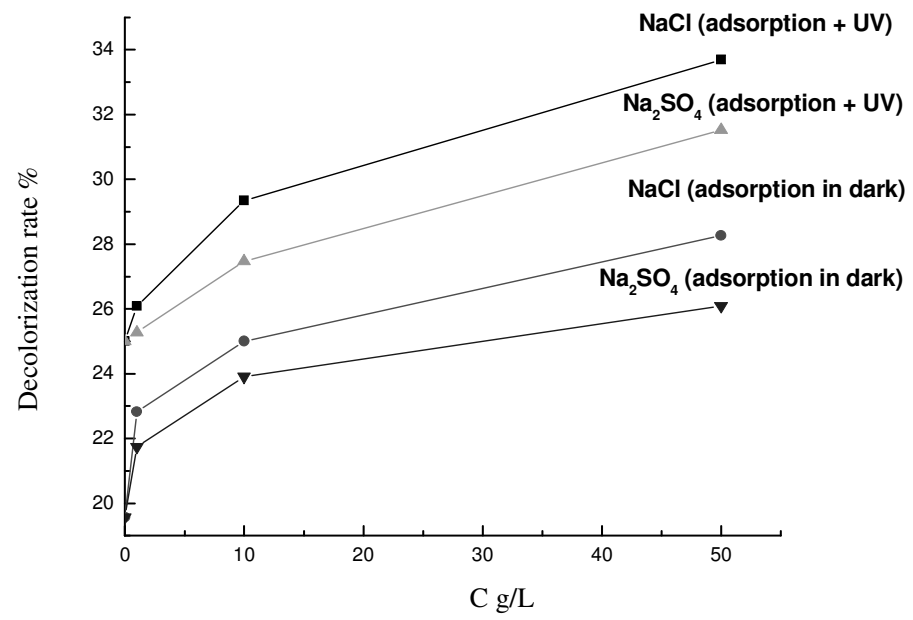

Figure 3. Influence of ionic strength on decolorization rate of EG loaded with titania
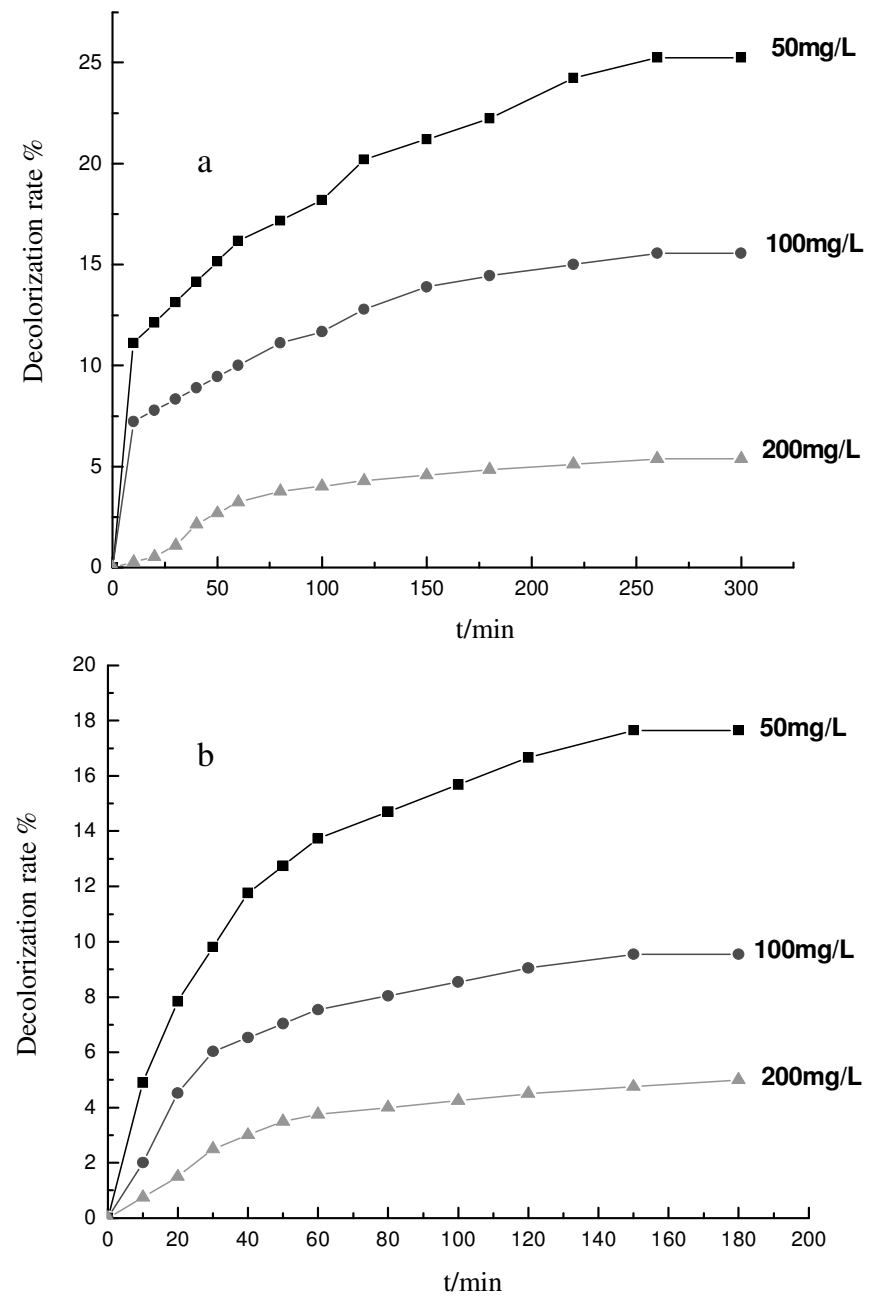


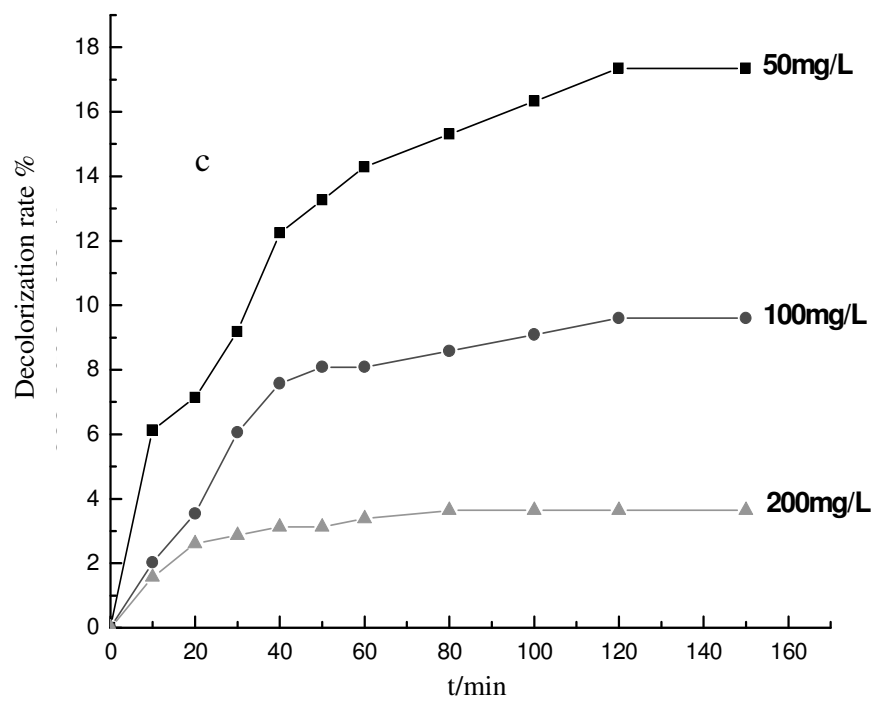

Figure 4. Influence of initial auramine lake yellow $\mathrm{O}$ concentration and temperature on decolorization rate (•) $50 \mathrm{mg} / \mathrm{L},(\bullet) 100 \mathrm{mg} / \mathrm{L},(\boldsymbol{\Delta}) 200 \mathrm{mg} / \mathrm{L}$ (a) $5{ }^{\circ} \mathrm{C}$, (b) $20{ }^{\circ} \mathrm{C}$, (c) $35^{\circ} \mathrm{C}$

\section{Decolorization kinetic models}

Both pseudo first- and second-order adsorption models were used to describe the decolorization kinetics data ${ }^{16,17}$. In both models, all the steps of degradation such as external diffusion, internal diffusion and decolorization are lumped together, the overall decolorization rate is proportional to either the driving force (as in the pseudo first-order equation) or the square of the driving force (as in the pseudo second-order equation).

First-order model: $\ln (D e-D)=\ln D e-k t$

Second-order model: $t / D=1 /\left(k D_{e}{ }^{2}\right)+t / D_{e}$

$k$, decolorization rate constant $\left(\mathrm{min}^{-1}\right.$ for first-order decolorization, $\%^{-1} \cdot \mathrm{min}^{-1}$ for secondorder adsorption); $t$, decolorization time ( $\mathrm{min}) ; D e$, equilibrium decolorization rate $(\%)$.

Since $D$ reaches a plateau $(D e)$ at equilibrium, $D$ values smaller than the $0.9 D e$ were used for analysis. The plots of: $\ln (D e-D)$ versus $t$ and $t / D$ versus $t$ were used to test the firstand second-order models and the fitting results are given in Table 3. According to the correlation coefficients, second-order model gives satisfactory fits. At the same time, the $D_{e, c a l}$ obtained from the intercepts is obviously inconsistent with the experimental data $D_{e, \text { exp }}$ in the first-order model. In the second-order model, the $D_{e, \text { cal }}$ agrees reasonably well with the experimental data. Thus, the second-order model is more suitable to describe the degradation kinetics data.

Based on the second-order model, the initial decolorization rate and half- decolorization times are estimated in Table 4 according to equation (4) and (5). Initial decolorization rate decreases with the increase of auramine lake yellow $\mathrm{O}$ concentration and halfdecolorization time is found to decrease with the increase in temperature.

$$
\begin{gathered}
u=k D_{e}{ }^{2} \\
t_{1 / 2}=1 /\left(k D_{e}\right)
\end{gathered}
$$

$u$, initial decolorization rate, $\% \cdot \min ^{-1} ; t_{1 / 2}$, half- degradation time, min 
Table 3. Comparison of decolorization kinetic models

\begin{tabular}{|c|c|c|c|c|c|c|c|c|}
\hline \multirow{2}{*}{$\begin{array}{c}C_{0} \\
\mathrm{mg} / \mathrm{L}\end{array}$} & \multirow{2}{*}{ 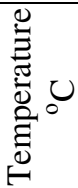 } & \multirow[b]{2}{*}{$\begin{array}{c}D_{e_{,},} \exp \\
\%\end{array}$} & \multicolumn{3}{|c|}{ First-order } & \multicolumn{3}{|c|}{ Second-order } \\
\hline & & & $\begin{array}{c}D_{e,,} \text { cal } \\
\%\end{array}$ & $K, \min ^{-1}$ & $\mathrm{r}$ & $\begin{array}{c}D_{e,}, c a l \\
\%\end{array}$ & $\%^{-1} \stackrel{K,}{\min ^{-1}}$ & $\mathrm{r}$ \\
\hline \multirow{3}{*}{50} & 5 & 25.25 & $19.12 \pm 1.09$ & $0.011 \pm 0.0008$ & -0.9726 & $26.97 \pm 0.0015$ & $0.0012 \pm 0.142$ & 0.9901 \\
\hline & 20 & 17.65 & $15.84 \pm 1.052$ & $0.0224 \pm 0.0008$ & -0.9949 & $18.68 \pm 0.0006$ & $0.0018 \pm 0.0006$ & 0.9995 \\
\hline & 35 & 17.35 & $20.75 \pm 1.052$ & $0.028 \pm 0.0009$ & -0.9959 & $16.65 \pm 0.001$ & $0.0027 \pm 0.0013$ & 0.998 \\
\hline \multirow{3}{*}{100} & 5 & 15.56 & $11.93 \pm 1.069$ & $0.013 \pm 0.0006$ & -0.9876 & $17.19 \pm 0.0016$ & $0.0017 \pm 0.0033$ & 0.9954 \\
\hline & 20 & 9.6 & $11.13 \pm 1.071$ & $0.023 \pm 0.001$ & -0.991 & $8.35 \pm 0.002$ & $0.0056 \pm 0.049$ & 0.9993 \\
\hline & 35 & 9.55 & $11.05 \pm 1.123$ & $0.03 \pm 0.002$ & -0.9816 & $9.02 \pm 0.003$ & $0.0064 \pm 0.0105$ & 0.9982 \\
\hline \multirow{3}{*}{200} & 5 & 5.38 & $6.53 \pm 1.046$ & $0.014 \pm 0.0004$ & -0.9945 & $5.6 \pm 0.0022$ & $0.0034 \pm 0.0022$ & 0.9994 \\
\hline & 20 & 5.0 & $4.68 \pm 1.055$ & $0.019 \pm 0.0007$ & -0.994 & $6.06 \pm 0.003$ & $0.0041 \pm 0.002$ & 0.999 \\
\hline & 35 & 4.43 & $3.72 \pm 1.068$ & $0.026 \pm 0.001$ & -0.9922 & $5.15 \pm 0.004$ & $0.0082 \pm 0.013$ & 0.9987 \\
\hline
\end{tabular}

The second-order kinetic models constants listed in Table 3 were used to estimate decolorization activation energy using Arrhenius equation (6). The slope of plot of lnk versus $1 / T$ was used to evaluate $E a$, which was found to be smaller than $40 \mathrm{~kJ} \mathrm{~mol}^{-1}$ (Table 4). The results proved that the decolorization of EG loaded with titania for auramine lake yellow $\mathrm{O}$ is mainly physical interaction. To judge the single decolorization ability of EG adsorption and titania (loaded in EG) photo-degradation, comparison experiment was carried out. The results (Figure 5) obviously proved that EG adsorption is stronger than that titania photodegradation.

$$
\ln k=\ln A-E a /(R T)
$$

$A$, pre-exponential factor; $E a$, activation energy of decolorization $\left(\mathrm{kJ} \cdot \mathrm{mol}^{-1}\right)$

Table 4. Kinetic parameters for the second-order model

\begin{tabular}{cccccc}
\hline$C_{0,} \mathrm{mg} \mathrm{g}^{-1}$ & Temperature ${ }^{\circ} \mathrm{C}$ & $u, \% \mathrm{~min}^{-1}$ & $t_{l / 2,}$ min & $E_{a} \mathrm{~kJ} \cdot \mathrm{mol}^{-1}$ & $\mathrm{r}$ \\
\hline \multirow{2}{*}{50} & 5 & 0.876 & 32.894 & & \\
& 20 & 0.633 & 31.226 & 16.80 & -1.000 \\
\multirow{3}{*}{100} & 35 & 0.755 & 21.166 & & \\
& 5 & 0.496 & 38.343 & & \\
& 20 & 0.392 & 18.625 & 27.55 & -0.9081 \\
200 & 35 & 0.523 & 16.189 & & \\
& 5 & 0.106 & 54.941 & & \\
& 20 & 0.151 & 48.713 & 18.30 & -0.9491 \\
\hline
\end{tabular}

\section{Analysis of possible decolorization mechanism}

In order to analysis the possible decolorization mechanism of auramine lake yellow $\mathrm{O}$ under EG adsorption and titania photodegradation, the absorption spectrum scanning among 190 900 $\mathrm{nm}$ were carried out before and after decolorization treatment. As showed in Figure 6, no new resultant occurs; the adsorbate is mineralized under the photodegradation of titania. So the decolorization mechanism would be: auramine lake yellow $\mathrm{O}$ in solution and adsorbed on surface of EG can jointly be photodegration by titania, mineralizing product are mainly $\mathrm{CO}_{2}$ and $\mathrm{H}_{2} \mathrm{O}$, adsorption of $\mathrm{EG}$ can improve the decolorization effect. 


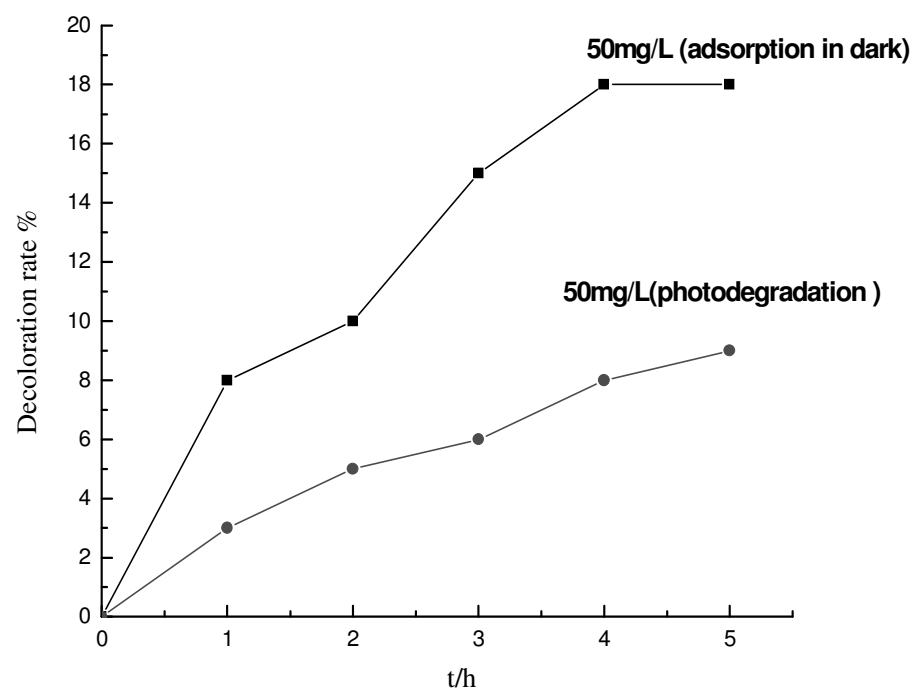

Figure 5. Comparison of EG adsorption and titania photodegradation

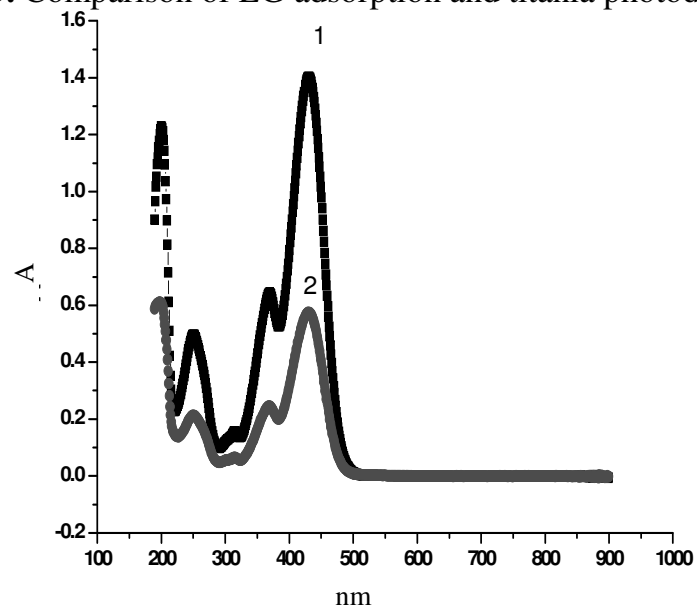

Figure 6. Absorption spectrums of auramine lake yellow $O$ (1) before decolorization (2) decolorization $5 \mathrm{~h}$

\section{Conclusion}

This study has proved that EG loaded with titania possesses a higher decolorization ability for auramine lake yellow $\mathrm{O}$ than the single EG adsorption or titania photo-degradation. Decolorization process was influenced by initial dye concentration, decolorization time and ionic strength. Ionic strength plays an important role in decolorization, higher ion strength or the presence of salts can improve the treatment of dye. The decolorization kinetic of auramine lake yellow $\mathrm{O}$ can be well described by the pseudo second-order kinetic model. The half-decolorization time of auramine lake yellow $\mathrm{O}$ is found to decrease with the increase in temperature. Decolorization of auramine lake yellow O on EG loaded with titania holds small activation energy and physical adsorption plays main role in the adsorbption and photodegradation process. 


\section{Acknowledgment}

This study was supported by Doctor Foundation of Hebei province Education Office (China, No.B2004402) and Doctor Foundation of Hebei University. We gratefully acknowledge their support during the study.

\section{References}

1. Yu R G, Qiao X J, Liu W H and Miao Y L, Adv in Fine Fetrochemicals, 2003, 4(10), 8.

2. Li J H, Liu Q Y, Li M and Liu Z R, Fine Chem., 2003, 20(6), 341.

3. Huang Y X, Zhou N L, Li L, Liu Y, Wei S H and Shen J, J Nanjing Normal Univ (Nat Sci)., 2005, 28(4), 57.

4. Zhu J P, J Hefei Univ Technol (Nat Sci Ed), 2001, 24(6),1158.

5. Mashiro T and Michio I, Carbon, 2000, 38(2), 199.

6. Pang X Y, Ren H L, Gong F, J Hebei Univ (Nat. Sci.), 2008, 28(5), 512.

7. Wang L N, Chen X, Zheng Y P, Kang F Y, Chen J F and Shen W C, Guide J Chinese Nonmeteal Mine Ind., 2004, 5, 59.

8. Yang L N, Master's Thesis, Hebei Normal University, Shijiazhuang, 2004.

9. Pang X Y, Lv P, Feng Y Q and Liu X W, Environ Sci-An Indian J, 2008, 3(2), 150.

10. Pang X Y, Lv P, Gong F, Ren H L and Liang X H, Chem J Internet., 2007, 9(12), 53.

11. Hachem C, Bocquillon F, Zahraa O and Bouchy M, Dyes and Pigments, 2001, 49(2), 117-125.

12. Zhang Z X, Chen L, Bao N and Chen D H, Protect Water Resour., 2006, 22(2), 59-62.

13. Li J H, Jia Z X, Feng L L and Liu S F, Non-metallic Mines, 2006, 29(5), 39-41.

14. Pang X Y, You T T, Su Y J and Chen Y, Non- metallic Mines, 2009, 32(5), 1-4.

15. Wu Z J, Joo H, Lee K, Chem Eng J., 2005, 112(1-3), 227-236.

16. Chiou M S and Li H Y, Chemosphere, 2003, 50(8), 1095-1105.

17. Chiou M S and Li H Y, J Hazard Mater., 2002, 93(3), 233-248. 


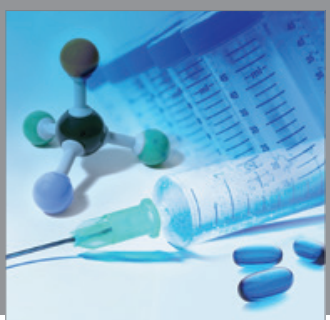

International Journal of

Medicinal Chemistry

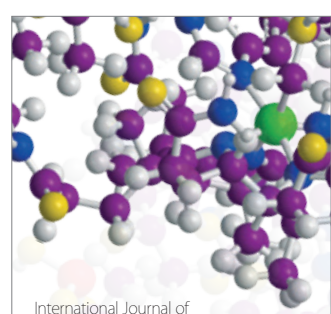

Carbohydrate Chemistry

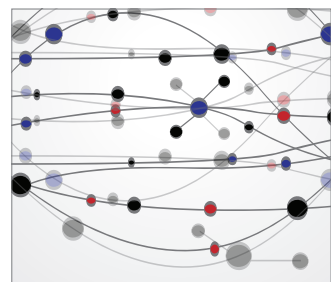

The Scientific World Journal
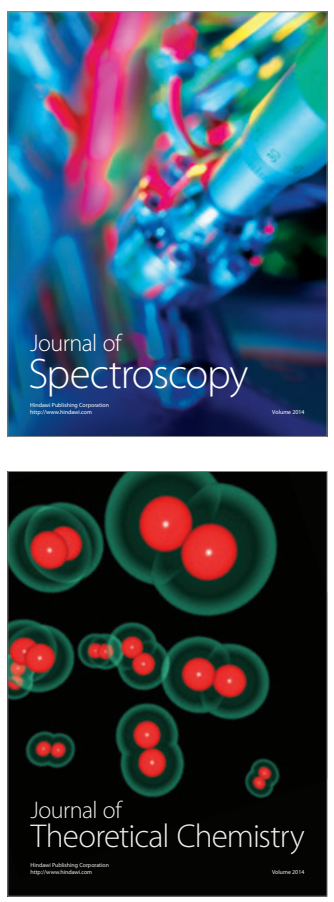
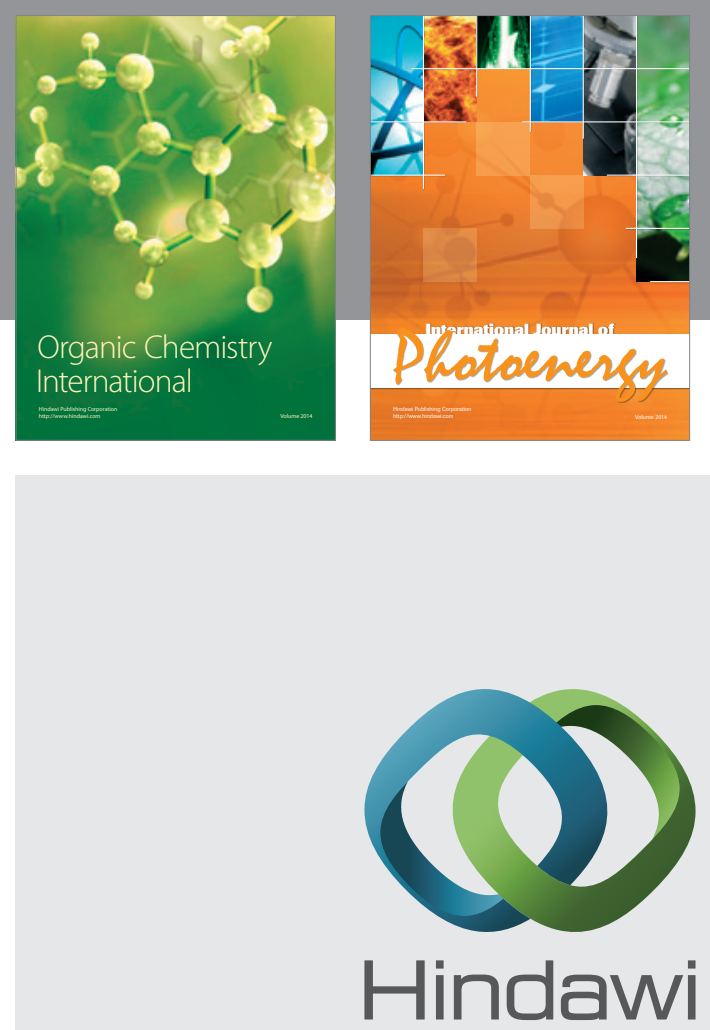

Submit your manuscripts at

http://www.hindawi.com
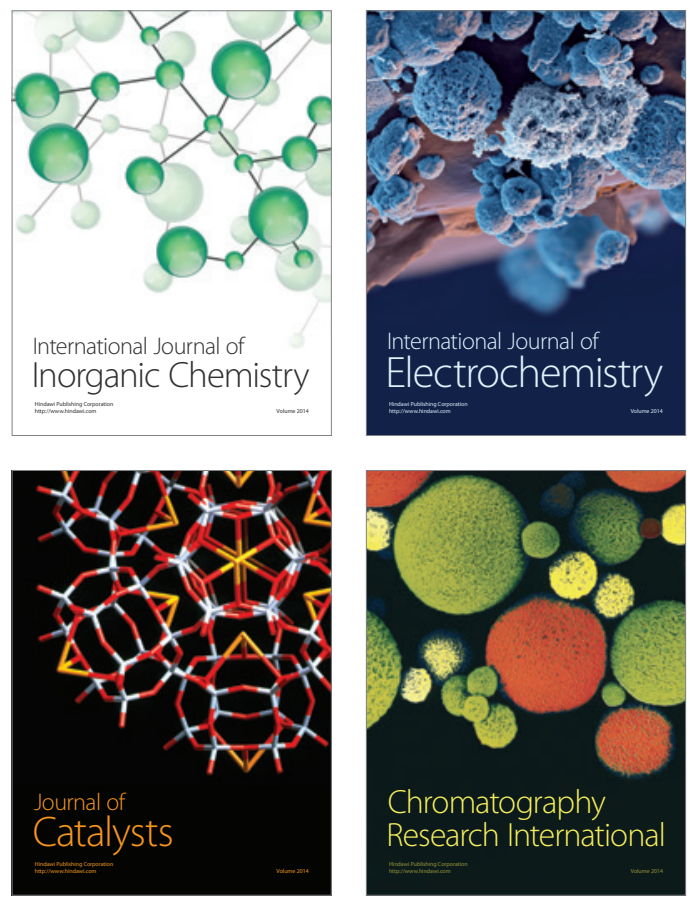
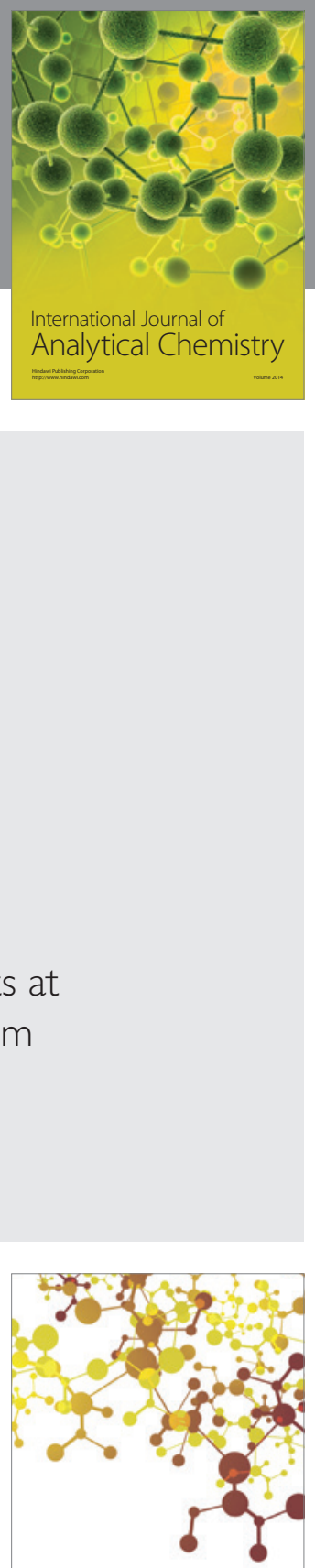

Journal of

Applied Chemistry
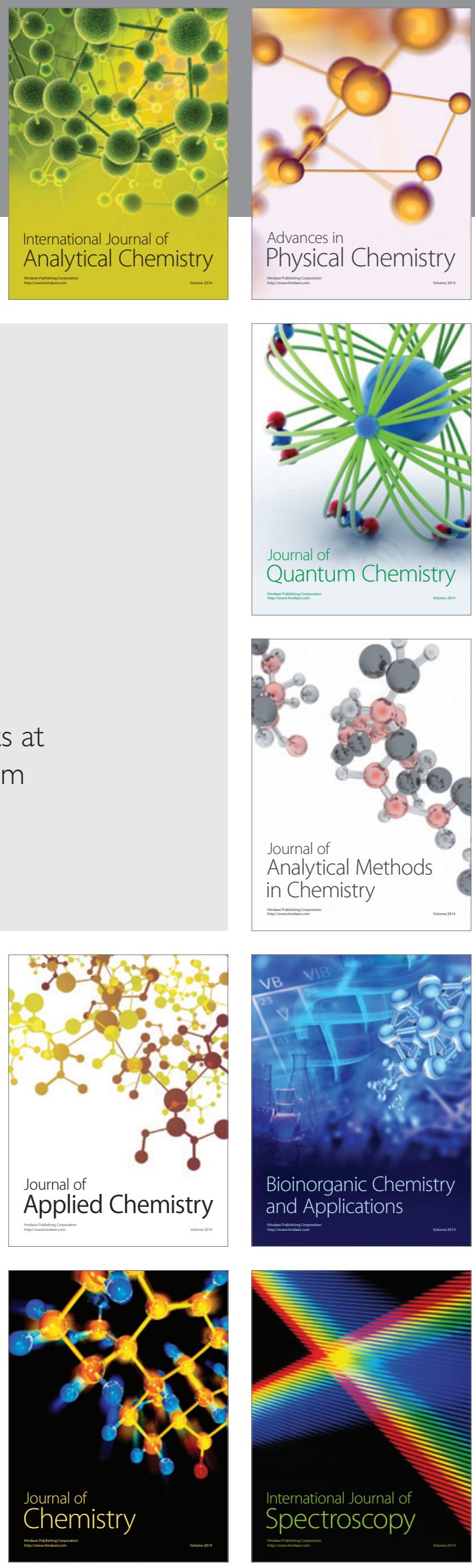